\title{
THE VARIABLE OF CREATIVITY AND PRE-SCHOOL EDUCATION
}

\author{
Georgiana Alexandra ȘERBU, \\ PhD. Student, University of Bucharest, \\ Romania \\ E-mail: serbu.virgil@yahoo.com
}

\begin{abstract}
Pre-school education as the first stage of institutionalized education comprises a series of activities that have as their origin the creation of a creative and autonomous personality that makes subsequent social integration possible. Thus, the variable of creativity plays a special role in the process of modeling the human personality and it is necessary that its stimulation be realized early. Given that the variable of creativity has multiple forms of manifestation, the role of education is to model it and stimulate it by virtue of a holistic formation. The purpose of this study is to identify the ways of expressing creativity among preschool children, as well as parents' opinions about the activities carried out in order to stimulate children's creativity. "Creativity is a social need." (Roco, p. 12) Education, as a factor of human educability, assumes an imperative role in the process of modeling human personality. The variable of creativity, through various forms of manifestation, influences the adaptability process of the human being and has defining influences in terms of building a personality according to the requirements imposed by the present, but also future society. Being a social need, creativity has the potential needed for a holistic, harmonious development that will lead to improvement and innovation. The need to stimulate creativity from an early age derives from the developmental needs and individual characteristics of children. Creativity should be seen as a necessary tool for a harmonious development that has the power to shape the human personality. Therefore, pre-school education, as the first stage of institutionalized education, has to make early use of the creative potential of the child.
\end{abstract}

Keywords: Preschool education; personality; creativity; stimulation of creativity;

\section{INTRODUCTION}

Creativity as a personality variable can influence the individual development of the child and therefore it is important that the aspect of the creative process be an imperative of early education.

The implementation of the new curriculum for preschool education includes changes in the kind of activities in kindergarten, with emphasis on the allocation of the number of hours for each type of activity provided by the instructional-educational program in the preschool institution. „,Therefore, early childhood education and care should be considered as the basis of education and training systems, which translates into ensuring optimal conditions for developing key competences in perspective. A coherent early education in all the environments involved (family, kindergarten, community, etc.) represents the necessary context for a balance between socio-emotional aspects, learning and well-being." (Curriculum for early education, 2019, p. 4). It is desired that the creativity variable be 
exploited early and therefore the importance of offering the child with learning experiences that aims to model a creative personality, capable of adapting to the requirements, increases, current, but also future of the society in continuous change and transformation.

\section{PRE-SCHOOL EDUCATION - ANALYSIS AND CONCEPT}

The education law no. 84 of 1995 starts the system of reform of the contemporary Romanian education. This deals with aspects based on certain essential principles or theses, according to Gheorghe Tomșa $(2005$, p. 17): „the principle of the global approach to change the education system, which aims at the hierarchy of innovative actions at the level of the macrostructural and microstructural fundamentals, the principle of the innovative restructuring of the system of education, which aims to highlight the direction of evolution of pedagogical change at higher levels of creativity, the principle of prospective employment of structural and systemic change, which aims to substantiate the reform at the psychological, philosophical and sociological level." Pre-school education represents the first institutionalized step in which the personality personality is modeled. Its importance derives from the educational ideal prescribed by the Law of National Education of 2011, article 3: „The educational ideal of the Romanian school consists in the free, integral and harmonious development of the human individuality, in the formation of the autonomous personality and in assuming a system of values that are necessary for personal fulfillment and development, for the development of the entrepreneurial spirit, for active citizen participation in society, for social inclusion and for employment in the labor market". Thus, preschool education acquires value in that the shaping of the child's personality, given that formal education is the first line in contact with the child.

Cornelia Ștefănescu (2005) referred to the preschool period as the age of psychobehavioral acquisitions that play a fundamental role in the level of adaptation and integration of the child in the subsequent evolution. In the preschool period, the child develops basic skills, such as food, clothing, hygiene, but also cultivates skills to gain personal autonomy because he learns how to do it alone. Also, in this period, the child forms his self-image and outlines his first personality traits. From the point of view of physical development, the child develops his musculature, "the stature increases, the definitive tooth buds are strengthened" (Stefanescu, 2005, p. 44).

Also, "the structural development and the fine differentiations from the functional training of the cerebral cortex, the separation of the areas of speech and the fixation of the asymmetrical domination of one of the two hemispheres continue, which imprints the right, left or ambidexterous nature of the child's craftsmanship. The development of the internal biochemistry becomes complex, accentuating the production of hormones at the level of the thyroid and the thymus, with effects on growth." (Ștefănescu, 2005, p. 44).

The imperatives of the pre-school education concern aspects regarding the process of social integration, communication and verbalization, formation of skills and skills, accumulation of knowledge, but also stimulation of memory, intelligence, creativity. Therefore, the need for early childhood institutionalization in pre-school institutions becomes an imperative. The sooner the child comes into contact with the kindergarten, the more easily the school integration and performance are achieved.

The child who attended the kindergarten, in addition to the knowledge, skills acquired, also has a predisposition to learning, still early, being familiar with the rules, norms, but also the learning techniques needed to complete the new schooling cycle. The 
intervention of the educator becomes a necessity and prevents the child's development needs, through the variety of activities proposed, the materials used, but also through the level of involvement and skill. The professional training of the staff of the preschool institution marks the educational activity carried out on children. Romiţă Iucu (2007) notes that education imposed interdisciplinary approach regarding professionalization. Monospecialization must be overcome, and the professionalization process must be viewed from a multi-disciplinary perspective. The need for professionalization has become a definite and useful thing. Emil Păun (2002) stated that ,the essential orientations regarding the professionalization for the teaching profession are largely influenced by the pluralism and the paradigmatic competition in the education sciences, where two great paradigms - the normative and the interpretative one - are confronted, rather complementary paradigms, than opposite".

The investment in pre-school education is due to the importance of this period in terms of acquiring knowledge, training skills and skills in behavioral, affective, intellectual, social, etc. In the program "Early education matters" (2000, p. 2) proposed by Judith L. Evans, Robert G. Myers and Ellen M. Ilfeld, the importance of early education for the development of the child's personality was discussed. Children up to eight years of age can learn more easily because of the easier handling of the objects around them, through exploration and experimentation, learning by error and trial. Children learn by doing, observing and manipulating until they are eight years old, then being caught in the "age of reason", when they begin to operate differently with certain concepts and can learn mental concepts, being less dependent on objects.

The study by Cristina Felfe and Rafael Lalive (2015) in Germany revealed important aspects of early education on children's personality development. It was found that there are significant differences between the children who attend kindergarten and those who do not attend. There was an improvement in motor skills, socio-emotional development and language of children who attended early education programs. Also, even if they came from precarious socio-economic backgrounds, children who participated in education programs had higher scores in terms of personality development. It has been observed that there are differences between boys and girls, boys being more influenced by such education programs.

The study concluded that in OECD countries, such as Belgium, Denmark, France, Germany, Iceland, Israel, Norway, Spain and Sweden, the education of children between three and four years is done in kindergarten, so that $90 \%$ of children go through the preschool environment. However, there are barriers that parents perceive to justify choosing not to send their children to kindergarten: the costs are too high for some low status families, the child's perception of being too low to complete the institutionalized kindergarten program, the perception according to which the mother must educate the child and not inform about the important role of the preschool environment on the development of the child's personality. The study revealed aspects regarding the role of the kindergarten and the parents' awareness regarding the preschool education.

Another study by Chung E.O., Fernald L.C.H., Galasso E., Ratsifandrihamanana L. and Weber A. in 2019 revealed issues regarding pre-school education and the influence of parents on the development of the child's personality. It was concluded that the family has an important influence in the formation of the child and the investment in the early education creates the premises for a further harmonious development with positive results during the school period. Also, the involvement of parents in early childhood education has positive effects on shaping their personality. 


\section{THE CONCEPT OF CREATIVITY}

\subsection{Creativity - the evolution of the concept}

Teresa Amabile (1996) considers creativity as the supreme innovation. P. Popescu Neveanu (1978) defined creativity as a complex personality formation. Mihaela Roco (2004) stated that the variable of creativity can be considered as a social need, since it has major implications on the development of the whole personality. Gheorghe Tomșa (2004) stated that there are several directions in the definition of creativity. One point of view would be that the variable of creativity can be interpreted as an aptitude or capacity to achieve something new and valuable, another perspective concerns the process by which the product is realized, and another one considers creativity as any new problem solving. There are five plans for manifesting the creative behavior delimited by I. Taylor: expressive, productive, inventive, innovative and supreme or emergent. In the expressive plane the basis of creativity takes place, in the productive one the individual is able to acquire some skills, information, but also working techniques, and in the inventive plan the person is able to correlate the information held with the new situations they are facing. The innovative plan involves a full understanding of a particular field, its fundamental principles, and the supreme or emergent plan aims at a limited number of individuals, being classified as the high plane of creativity. The emergence of creativity is influenced by a number of factors that influence both the creative process and the final product achieved after the emergence and stimulation of creativity.

The factors of creativity are intellectual, characteristic and social in nature. Iacob Cosmovici (2008) argues that a main component of creativity is the imagination defined as a psychic process that results in obtaining reactions, new psychic phenomenon from a cognitive, affective or motor point of view. The traits of imagination seen as true characteristics of creativity aim at fluidity, plasticity and originality. The use of exercise repeatedly gives importance to another factor of creativity, namely memory. Also, the volume of information, their variety and experience are factors that put their mark on memory. The intelligence of a person can influence creativity and the creative process through the connections they make, as well as through the varied knowledge they possess as a result of their processing. You can see the connection between creativity and intelligence, given that creativity is perceived as an ability of the individual to solve new problems. The intervention of the will, as well as the predispositions and the intellectual capacities, can influence the development of a person's creativity. It is known that heredity is a determining factor in the development of a person's personality, so that the appearance of creativity is closely correlated with the genetic material that the individual has. Also, from the character point of view, the will and the perseverance that the individual has in the accomplishment of tasks contribute to the development of the sides of his personality, including the creative side. The motivation, the demands imposed by the company and the development stage of the discipline are other factors on which creativity depends. The creative process, like any process, comprises a series of fundamental steps that define the creative side of the personality of the human individual. Iacob Cosmovici (2008) recalls the incubation period which involves collecting information, delimiting the problem, incubation period in which efforts are made to find solutions, lighting which means finding solutions and checking which involves identifying and removing errors.

The creativity variable influences the development of the whole personality. Over time, there have been many theories that explained the phenomenon of creativity. 
The psychoanalytic theory of Sigmund Freud ,explains the phenomenon of creation starting from the theory of sublimation, considering that the phenomenon of creation can be determined, generated by the tension caused by the tendencies, the impulses repressed in the unconscious, tendencies that can appear in disguised forms, in forms resistant to the social existence" (Popescu, 2007, p. 14).

A. Adler 's theory considers creativity as a means by which the individual evolves, adapts, self-realizes and plays a role in society. Associationism defines creation as ,,a process of association between certain elements, leading to the emergence of new combinations, a process that is subordinate to certain demands or ends (J. Maltzman, 1960, SA Mednick, 1962). The level of creativity of the obtained results is evaluated according to the associated elements, which must be least related to each other" (Popescu, 2007, p. 15). The gestalt theory represented by W. Köhler, M. Wertheimer, R. Arnheim, R. Mooney, sees the creative process in permanent relation with the whole, with the internal structure of the respective phenomenon. The behaviorism represented by C.F. Osgood, J. Rossman, J. Parnes, R. Hyman emphasizes the instrumental conditioning, the stimulus-response relationship, the decisive influence in the creative process being of the parents through the educational value of the rewards granted to the children who can determine the orientations for creative thinking. Humanists (A. Maslow, C. Moustakas, C. Rogers, R. May, E.G. Schachtel) consider creativity as a general human potential, with environmental factors having the influence of unleashing the potential of each individual. The (interpersonal) cultural theory represented by M.J. Stein, G. Murphy, S. Arieti, H. H. Anderson, M. Mead, M. Tumin, P. Matusseck „emphasizes the role of cultural factors in the environment in the genesis and development of creation." (Popescu, 2007, p. 17). Guilford presents a systemic conception of creativity, revealing its components. In 1971, P. Popescu-Neveanu proposed a model by which creativity is seen as the result of the interaction between aptitudes and attitudes (Popescu, 2007). Cognitivists see creativity as a combination of data in order to find concrete solutions.

Integrative models of creativity have been treated by many authors. The theory that belongs to Teresa Amabile concerns the intrinsic motivation in children. They tend to show their creativity through self-interest and self-determination. They consider that they are much better in control of the activities they choose for themselves (Popescu, 2007). Gardner delimits the general framework of analysis of the creative phenomenon at the subpersonal level, where the biological substrate of creativity is found, at the personal level where the cognitive, motivational and creative personality factors are found, at the intrapersonal level where the field in which the individual manifests his action is described creative and at the multi-personal level where the influences of the family and professional environment on the creative action are delimited and described (Popescu, 2007). In the model proposed by M. Csiksentmihaly, creativity, as a complex phenomenon, is a consequence of the interaction and interdependence between the components of social institutions, the cultural field that preserves and transmits the creations and the individual that produces changes in a certain field (Popescu, 2007).

\subsection{Creativity - current researches}

In the specialty literature, the phenomenon of creativity has long been pursued by researchers who wanted to explain both the appearance of creativity and the methods of stimulation, but also the barriers involved in the creative process. Turkish researchers Elif 
Celebi and Esra Unluer (2010) conducted a study that revealed the connection between the manifestation of creativity and the use of children's play materials. Due to the technology and digitization, the symbolism manifested through creativity plays an important role in the development of the child's personality. It has been found that children do not creatively use play materials, symbolically because they do not have frequent contact with such real materials. The study was carried out in two stages: in the first stage, the children got in touch with toys, but also with real materials such as the telephone, kitchen objects, etc. They chose to play with real materials. In the second stage, the children used the play materials in a real way, without being creative. They did not give another value to the used objects, but used them as in real life. Therefore, the conclusion of the study was that it is necessary for the children to have early contact with real objects, in order to make connections, to offer them another value, to be able to show their creativity.

Researcher Elena Lupu (2011) wanted to correlate the development of creativity with physical activities. Starting from Horst H. Siewert 's „Creativity Tests”, which considered that „two skills can be developed simultaneously, and not one after another", the study confirmed the hypothesis that physical activities influence the emergence of creativity. Children who play sports develop creative skills, are more resourceful, more attentive, more disciplined, which leads to the development of a more creative personality than children who do not play sports. By virtue of this fact, it is considered necessary the physical effort made through the physical activities. Therefore, the introduction of physical activities from kindergarten has positive effects on children's creativity.

The research study proposed by Hale Hocer (2012) sees the development of creativity through artistic-plastic activities. The research was carried out on a sample of 10 teachers and started from the study of Rozario and Collazo from 1981, which talks about imitation and the tendency of the teacher to lead the student in making a product similar to the one he made. In this way creativity is inhibited. At present, it is desired that the child make new, original products and that is why ,education through art” correlated with ,education for art 's sake”. The conclusions of the study were that through the artistic-plastic activities the fine musculature of the hand is developed and the coordination of the eye and hand is developed and creativity is improved. The Turkish researchers Belma Tugrul and Hatice Uysal (2014) conducted a research on the creativity of teachers and their personality implications on stimulating children's creativity. The staff involved in the study answered 4 questions: „Do you consider yourself a creative person? Do you know a creative person and why do you think he/she is creative compared to you? What are the characteristics of a creative person? What is creativity in your opinion? Draw the picture of creativity." The study showed that creative teachers form creative personalities for children. M. I. Popescu, N. I. Moraru, A. Sava (2015) conducted a study on family barriers in the development of preschoolers' personality. The objectives of the research were to validate an instrument that measures the parental style, to correlate the child's creativity with the parental attitudes and to identify the influence of the parental style on the child's level of creativity. The study started from the researcher R. Stenberg according to which there are three aspects of creativity: synectical, analytical and practical ability (,triarchic theory of human intelligence"). Following the research carried out, the objectives were met and an instrument measuring the parental style was validated. It was also found that parenting style influences children's creativity. Natalia V. Vinichuk and Maria V. Dolgova (2016) addressed the subject of creativity related to happiness. Following the study, it was found that when the level of children's creativity is 
high, they interpret happiness as an emotional phenomenon and happiness is built as a social interaction with other people. When the level of children's creativity is low, happiness is impersonal, manifested by concrete things that the child holds. Thus, creativity is correlated with happiness and influences the development of the whole personality of the child.

\section{CASE STUDY ON THE MANIFESTATION OF CREATIVITY}

\section{The justification for choosing the case}

In the kindergarten educational activities, we have seen the known differences on early manifestation of creativity, which is why I tried to delimit the relationship between the expression of children's creativity and stimulation techniques, and the role of social media on preschool children. Some children more easily handle working materials and show increased availability in correlating new content with old ones, some freely draw much easier compared to others, combine working techniques, materials and colors much easier and without support, while others exhibit rigidity, all leading to a different manifestation of creativity. I chose these two subjects because one showed increased creativity compared to the other, although both attended the same preschool and had the same educators.

\section{Identify and highlight the importance of the case}

The variable of creativity manifests itself early, and its stimulation can be achieved more easily among preschool children due to the fact that they are constantly modeling knowledge, curiosity. Creativity can be exploited in various forms. Among preschool children can see differences in behavioral, intellectual, in which the process of adaptation and socialization, for which the choice of subjects to learn more about the characteristics and difficulties is one way that you can customize and differentiate act education. After observing the differences of this kind, I decided to choose to research the two subjects precisely in order to be able to overcome some difficulties regarding the stimulation of creativity.

The objectives of the case study were to reveal the differences of manifestation of early creativity among two children aged 5 years with different socio-economic status, to the differences of the socio-economic and cultural environment of the child on stimulating creativity, identifying methods to stimulate early creativity, as well as removing the barriers involved in the creative process during the preschool period. I used two preschool subjects, female.

The purpose of the case study is to determine the ways to stimulate early creativity.

Analysis of the socio-economic and cultural environment.

In the first case, the subject „S” comes from a high socio-economic status. Both parents have university studies, having the occupation of university professor and engineer. They also represent a family model in the community they belong to.

In the second case, the subject „E” comes from a modest family, with parents with high school education, but with a very high level of involvement in the education of children. Although the material possibilities are much lower, the family of the subject „E” participated equally with that of the subject „S" both from a financial point of view, as well as the availability of time and involvement in children's education.

After applying the tests, I found out that the level of creativity differs, although both girls attended the same kindergarten and had the same educator. Subject „S" showed an increased level of creativity compared to subject „E”. The test used was the flexibility test of thinking adapted after Mihaela Roco, from which the subjects were tasked to find as many interpretations and meanings as possible for certain drawings. The test 
with experimental model of stimulation and interpretation was used, in which the subjects reproduced a flower and received a certain score depending on the reproduction made and the novelty elements brought to the drawing.

\section{Factors}

One cause of the different manifestation of creativity is genetic. The factor of heredity has an influence on the whole personality. To sow, the socio-economic factors imprint the variable of creativity. The subject ,S" has access to didactic materials provided by parents, experiences the contact with nature with the family, benefits from opportunities for exploration through visits, walks, trips with the family, all of which have influence on the manifestation of creativity. On the other hand, the subject „E” does not have access to the same opportunities offered by the family.

One other factor that could influence the development of creativity is the cultural situation of the family and education level. The subject „S” comes from parents with higher education, with a higher level of education, with a cultural situation different from that of the subject „E”.

\section{Subject characteristics}

However, the subject „S” has a special temperament. She is selective, she does not perform all the tasks unless she wants, she is not attracted by the activities that require patience, she is an explosive person, with a strong character, she has high intellectual abilities, a solid memory, her imagination is very rich, and her inventiveness is a quality that defines it. The subject „E” fulfills all tasks, is hardworking, dedicated to learning, but with a weaker memory, poor imagination and an introverted character.

\section{Proposed intervention program}

Following the discussions with the teachers from the commune, we could find that there is a need to carry out extracurricular activities, which is why we decided to create a creative program in which the children of large group participate, in order to have the necessary learning experiences for stimulating creativity. Both subject „S” and subject „E” participated in the program of creative activities, along with 10 other subjects. As a result of the activities carried out, we were able to find changes both in terms of subject „S" and subject „E”.

To track the initial level of creativity, we used a reinterpretation of Mrs. Creativity and Originality Test. Prof. Roco M. The children have determined which object has a round shape. They exemplified the ball, the wheel, the clock. Subject "S" considered that the round shape is characteristic of "a flower medium". Also, the children exemplified what makes noise: the creaking of the door, the car, the toys. The subject "S" considered that what produces noise is "bee buzz" and "when the mother raises the tone to it". Another evidence proposed was that the children made an imitative drawing of a flower. The subjects made faithful copies of the proposed flower, but the subject "S" made a faithful copy of the proposed model, but also added small details such as butterflies, bees, hearts. Thus, when asked why he did not respect the evidence, the subject "S" explained that "this is the most beautiful flower".

Subject „S" has developed attention, could focus better on the task, and with the ability to choose the materials used and strengthened confidence in their decisions. Subject „E" has developed self-esteem and self-confidence, shaped his memory and stimulated the process of communication with other children. Following the implementation of this intervention program, creativity tests were reapplied and it was found that preschoolers 
enrolled in this type of extracurricular activities have undergone positive changes, being more creative and involved in the subsequent kindergarten activities.

The creative program carried out in the rural area was concluded by an exhibition of children's works, and the parents were the subjects of a questionnaire from which we could find relevant information regarding the creativity variable. The survey method, is an interactive method that involves the direct exchange of information between the researcher and the subjects under investigation. This makes it possible to collect data from a large mass of subjects. The communication relationship encountered in the case of investigations is dual, but strongly asymmetric, as the researcher is the one who designs, conceives, formulates and addresses a series of questions, stimulating the investigated subjects to answer" (Bocos, 2003, p. 76). The specific instrument used is the questionnaire, ,which is a system of written questions, well structured, in a certain sequence based on logical considerations. The questionnaire comprises two parts: the introductory part, where the subjects are motivated the need for its application and clarifications are made regarding the completion, insisting on the importance of the sincerity with which the answers are given; the questions themselves" (Bocoş, 2003, p.77).

The questionnaire addressed to the parents wanted to highlight the parents' opinions regarding the activities carried out within the creative club. This questionnaire included a number of ten closed questions which sought to find out what is the opinion of parents about such activities, what changes have occurred to their children and whether such activities are useful for the development of creativity. All the subjects involved in the questionnaire had affirmative answers regarding the role of extracurricular activities in developing children's creativity.

The conclusions of the proposed questionnaire releaved that the children are more creative and willing to participate in such activities, which is why it is hoped that such educational programs will continue in the future, the role of extracurricular activities being decisive in shaping the child's personality.

\section{CONCLUSION}

The study conducted in rural areas has revealed important aspects in which the creative process of preschool children. Extracurricular activities can influence the emergence and stimulation of creativity from an early age, and in rural areas it is necessary to involve teachers in such activities that support children in the process of modeling personality, and implicitly creativity.

The parents of the children from the rural area want to carry out extracurricular activities, but, for lack of financial resources, they decide not to allow the children to take part in such activities. Due to the small number of children in rural areas, non-formal activities end before the proposed date. Creativity can be stimulated by artistic-plastic activities. The children form a positive self-image, fulfill social roles in the micro-group of which they belong, become responsable, eager to learn, curious, communicative. Following the proposed creation program, the subjects involved became more creative.

The socio-economic and cultural environment impresses the child's development, the heredity factor is important, the family's intervention in the child's education plays a decisive role, and the educational influence on the part of the preschool institution plays a decisive role in the modeling of the child's personality. Creativity manifests itself differently, under the influence of various factors, the proposed activities being very important. 


\section{BIBLIOGRAPHY:}

[1] Amabile, Teresa. Assessing the Work Environment for Creativity . in The Academy of Management Journal . (1996). Vol. 39. No. 5.

http://people.wku.edu/richard.miller/amabile.pdf

[2] Bocoş, Musata. (2003). Theory and practice of pedagogical research . Cluj-Napoca: House of Science Book .

[3] Celebi Oncu, Elif, Unluer, Esra. Preschool children use of play materials creatively. Procedia Social and Behavioral Sciences, 2 (2), 4457-4461. https://doi.org/10.1016/j.sbspro.2010.03.711.

[4] Chug, E. O., Fernald, L.C.H., Galasso, E., Weber, A., Ratsifandrihamanana, L. (2019). Caregiver Perceptions of Child Development. A Cross-Sestional Study. The World Bank Development Research Group.

[5] Cosmovici, A., Jacob, Luminița. in Cucoș, C. coord. (2008). Psycho-pedagogy for the final exams and didactic degrees. Iasi: Polirom Publishing House.

[6] Evans, J.L., Myers, R.G., Ilfeld, E.M. (2000). Early Childhood Counts. A Programming Guide on Early Childhood Care and Development. Washinton: The International Bank for Reconstruction and Development/ The World Bank.

[7] Felfe, C., Lalive, R. (2018). Does early child care affect children's development?. Journal of Public Economics, 159, 33-53 https://doi.org/10.1016/j.pubeco.2018.01.014

[8] Hocer, Hale. The evaluation of the art activities applied in preschool education programs in terms of self-expression opportunity given to children. Procedia-Social and Behavioral Sciences, 51 , 289-295. https://doi.org/10.1016/j.sbspro.2012.08.161.

[9] Iucu, R. (2007). Teacher training. Bucharest: Humanitas Educational Publishing House.

[10] Lupu, Elena. Study regarding the impact of motion games on the intellectual-motric development of preschool children. Procedia - Social and Behavioral Sciences, 30 , 1209-1214. https://doi.org/10.1016/j.sbspro.2011.10.235.

[11] Păun, E. (2002). Professionalization of the teaching career. Professional standards for the teaching profession. Bucharest: National Council for Teacher Training.

[12] Popescu, Gabriela. (2007). The psychology of creativity. Third edition . Bucharest: Romania Foundation Publishing House tomorrow.

[13] Popescu, MI, Moraru, A., Sava, NI Family barriers in the development of creativity in preschoolers . Procedia - Social and Behavioral Sciences, 187, 601-606. https://doi.org/10.1016/j.sbspro.2015.03.112.

[14] Popescu, Neveanu, P. (1978). Dictionary of psychology . Bucharest: Albatros Publishing House.

[15] Roco, Mihaela. (2004). Creativity and emotional intelligence. Iasi: Polirom Publishing House.

[16] Ftefănescu, Cornelia. in Tomșa, Gh. (coord.). (2005). Preschool and school psychopedagogy. Bucharest: Pre-school Education Magazine Publishing House.

[17] Tomșa, Gh. (2004). in Creativity in education . Focșani: Terra Publishing House.

[18] Tugrul, Belma, Uysal, Hatice, Guneș, Gokhan, Okutan, N. Șermin. Picture of the creativity. Procedia - Social and Behavioral Sciences, 116, 3096-3100. https://doi.org/10.1016/j.sbspro.2014.01.714.

[19] Vinichuk, Natalia, Bolgova, Maria V. The image of creativity among children with different levels of creativity. Procedia - Social and Behavioral Sciences, 233 , 481-485. https://doi.org/10.1016/j.sbspro.2016.10.198. 